\title{
Organização do ensino de matemática na perspectiva histórico-cultural: um processo didático-formativo ${ }^{1}$
}

\author{
Patrícia Lopes Jorge Franco², \\ Andréa Maturano Longarezi ${ }^{3}$ \\ Fabiana Fiorezi de Marco $^{4}$
}

\begin{abstract}
Resumo: O artigo apresenta contribuições da perspectiva histórico-cultural e Teoria da Atividade no processo formativo de uma professora de matemática do Ensino Fundamental, na escola pública municipal de Ituiutaba - MG. A partir de Leontiev (1978), Davidov (1986), Vigotski (1984) problematiza como a organização do ensino para o desenvolvimento do pensamento e conceitos teóricos algébricos, se constitui em conteúdo e forma do processo formativo da professora. A pesquisa desenvolve-se pelo materialismo histórico-dialético e caracteriza-se como de intervenção didático-formativa. Durante o processo são produzidos, colaborativamente, três atividades orientadoras de ensino com conceitos algébricos, dentre as quais se discute um episódio composto de uma cena, com três unidades de análise: compartilhamento/interações; apropriações/objetivações; atribuição de sentido. As unidades revelam o modo da professora atribuir sentido às ações na práxis docente, na unidade de sua atividade prática e teórica.
\end{abstract}

Palavras-chave: Perspectiva histórico-cultural; ensino de matemática; teoria da atividade; intervenção didático-formativa.

\section{The organization of mathematics teaching from the historical cultural perspective: a teaching-formation process}

\begin{abstract}
The article presents contributions from the historical-cultural perspective and Activity Theory in the formative process of a math teacher of elementary school in the public school of Ituiutaba - MG. From Leontiev (1978), Davidov (1986), Vygotsky (1984) discusses how the organization of teaching for the development of algebraic thinking and theoretical concepts, constitutes content and form of the training process of the teacher. The research develops historical and dialectical materialism and is characterized as a didactic-formative intervention research. During the process are produced collaboratively three guiding teaching activities with algebraic

1 As autoras agradecem o apoio recebido da CAPES por ocasião do financiamento do projeto "Didática Desenvolvimental no contexto da escola pública brasileira”, no âmbito do projeto Observatório da Educação (OBEDUC), durante os anos de 2013-2015, ao qual, a pesquisa esteve vinculada.

2 Doutora em Educação pela UFU em 2015. Coordenadora da Educação Continuada da Secretaria Municipal de Educação, Esporte e Lazer de Ituiutaba/MG. E-mail: patricia.jfrancon1@gmail.com.

3 Doutora em Educação Escolar pela UNESP/Araraquara em 2001. Professora do Programa de Pós-Graduação em Educação da UFU. E-mail: andrea.longarezi@ufu.br.

4 Doutora em Educação pela FE/Unicamp em 2009. Professora do Programa de Pós-Graduação em Educação e do Programa de Pós-Graduação em Ensino de Ciências e Matemática, ambos da UFU. E-mail: fabiana.marco@ufu.br.
\end{abstract}


concepts, among which discusses a compound episode one scene with three units of analysis: Sharing / interactions; appropriations / objectivations; attribution of meaning. The units show the teacher the way to ascribe meaning to the actions in the teaching practice in the unity of her theoretical and practical activity.

Keywords: Historical-cultural perspective; teaching of math; activity theory; didactic and formative intervention.

\section{Introdução}

O trabalho docente constitui-se um dos temas recorrentes das políticas públicas educacionais e do universo acadêmico. Por um lado, o sistema educacional nacional, estadual e municipal coloca regras ao professor, regula e exige resultados quantitativos de um tipo de ensino focado na "transmissão" de conhecimentos e na "progressão-aprovação escolar". Afinal, por esse parâmetro o professor também passa a ser avaliado como "bom" profissional. Tais resultados não garantem e não definem a essência da atividade de ensinar e estudar. Assim, a atuação do professor ocorre sob fortes pressões e exigências do sistema educacional para atingir resultados quantitativos de desempenho escolar.

Por outro lado, as ações, condições objetivas e subjetivas dos professores, nem sempre lhes possibilitam atingir esse resultado/produto, que por vezes, pode estar bem distante de um desenvolvimento qualitativo dos estudantes. Nesses casos, o professor pode apresentar tendências de uma relação alienada na execução do ensino. Entende-se que, nessas fortes pressões, via verticalização do sistema educacional, muitas vezes, até podem ocorrer aprovações escolares, todavia elas não revelam o nível de apropriação conceitual dos estudantes, se empírico ou teórico. Tais aprovações nem sempre demonstram o que se espera do conteúdo e da forma de um ensino para o desenvolvimento: desenvolver integralmente o estudante e promover a apropriação conceitual, no nível teórico.

Por isso, as inferências levam supor que diante de uma inadequação didática, os estudantes podem apresentar tendências de uma relação alienada na consecução do "estudo", pois as ações, as condições, os conteúdos e a forma desse processo de estudar, não estão em correspondência. O conhecimento, nesses casos, deixa de operar como um instrumento de ampliação/desenvolvimento de suas capacidades.

Nesses casos, como um processo formativo docente poderia contribuir com o desenvolvimento qualitativo do trabalho educativo, e, consequentemente, dos estudantes? Esse processo conseguiria proporcionar aos sujeitos o movimento dialético da dimensão humana em si e para si?

Diante do exposto, torna-se importante questionar se o tipo de trabalho educativo conseguiria realizar a função de mediadora no processo de formação de um estudante mais humano e consciente de sua participação no mundo, enquanto ser 
individual e social. Isso implica na produção e criação de novas relações no ensino e estudo. De igual modo, requer repensar sobre o conteúdo e a forma do processo formativo docente, tendo em vista superar a condição de mera reprodução, para a condição de produção de si mesmo e do mundo, tanto do professor ao ensinar, como do estudante ao estudar.

Para que os sentidos de um processo formativo possam se objetivar na sua significação social, há de se estabelecer outra relação qualitativamente nova, onde o objeto desse processo possa satisfazer as necessidades formativas docente, se relacionar com o motivo e o objetivo da atividade de ensinar.

As discussões nesse artigo têm por objetivo apresentar como o aporte teórico-metodológico da Psicologia Histórico-Cultural (PHC) da atividade e do ensino desenvolvimental contribuíram com o processo formativo docente, decorrente de uma pesquisa ${ }^{5}$ realizada junto a uma professora de Matemática, do Ensino Fundamental II, em uma escola pública municipal de Ituiutaba - MG. Nesse recorte, discute-se como a organização de um ensino para o desenvolvimento integral do estudante, em particular, seu pensamento e conceitos teóricos algébricos, se constitui em conteúdo e forma do processo formativo da professora. O ensino e a aprendizagem, na sua relação com o desenvolvimento, tornam-se conteúdo e forma do seu percurso formativo.

\section{Fundamentação teórica}

O processo formativo da professora ancorou-se nos constructos teórico-metodológicos da perspectiva histórico-cultural, a partir de Vygotsky (1984); no ensino desenvolvimental, em Davidov (1986), e, mais especificamente, no conceito de atividade, postulada por Leontiev (1978, 197[-], 1974). Este autor define atividade como sendo "processos específicos que exercem uma ou outra relação vital, quer dizer, ativa, entre sujeito e a realidade" (Leontiev, 1974, p. 43-tradução nossa). Para este autor, na atividade existe uma relação triádica (sujeito-atividade-objeto) que se constitui historicamente na vida em sociedade, nos processos de trabalho coletivo e de necessidades humanas orientadas por finalidades. Nesse enfoque, o objeto é tomado como algo que realiza a relação do homem com o mundo atendendo a uma necessidade que lhe é inerente.

Para o referido autor, são essas relações sociais que o homem estabelece com o mundo, as que desencadeiam as inter-relações de sua atividade. Na concepção leontieviana, por atividade compreende-se um processo psicologicamente determinado pelo seu objeto (conteúdo) corresponder com o elemento objetivo que move

5 Pesquisa intitulada: "O desenvolvimento de motivos formadores de sentido no contexto das atividades de ensino e estudo na escola pública brasileira”. 2015 · 363f. (Tese) Programa de Pós-Graduação em Educação. Universidade Federal de Uberlândia, MG. 2015. 
o sujeito, ou seja, com o seu motivo. Nessa direção, ele afirma que as necessidades decorrem da atividade (interna e externa) do sujeito e só podem ser objetivadas, na relação objetivo-objeto (conteúdo) de tal atividade.

Portanto, acredita-se que a relação objetivo-objeto (conteúdo) para o qual o estudante precisa direcionar suas ações (pelo menos se espera), reside no desenvolvimento integral de sua personalidade, em especial, seu pensamento teórico, formação de conceitos científicos e ações mentais. De forma que, a organização didática do ensino, para essa formação, se constitui na relação objetivo-objeto (conteúdo), para o qual as ações da atividade de ensino precisam estar direcionadas.

Os produtos subjetivos desses processos são as mudanças qualitativas no desenvolvimento da professora, nos aspectos didático-pedagógicos do ensino. Os produtos objetivos desses processos são as transformações da realidade, isto é, das relações sociais e concretas entre professor e estudantes, professor e métodos de ensino, entre os próprios estudantes e destes com o objeto-conteúdo do conhecimento.

De modo que, na pesquisa realizada, o processo formativo da professora organizou-se a partir dos elementos constitutivos da estrutura interna psicológica da atividade pedagógica: necessidade, objeto e motivo (elementos de orientação).

Nesse processo, buscou-se criar condições para gerar novas necessidades como promoção da aprendizagem e humanização dos estudantes, na relação com o seu desenvolvimento integral e, impulsionada pelo motivo de proporcionar o desenvolvimento integral dos estudantes, na sua relação com a formação do seu pensamento teórico, ações mentais e conceitos teóricos. Tais necessidades e motivo se inter-relacionaram com o objeto de ensino.

Tais elementos orientaram a execução do processo didático-formativo da professora, a nível consciente, da seguinte maneira:

Ações: i) Leitura de textos sobre a PHC: educação, ensino, desenvolvimento, didática, lógica dialética, formação das ações mentais, pensamento teórico; ii) Planejamento didático de ações de aprendizagem envolvendo conceitos algébricos, bem como, a confrontação entre didática tradicional e didática desenvolvimental; iii) Ações de autoavaliação.

Operações: i) Dinâmicas de estudo participativas e colaborativas - pesquisadora e professora; ii) Registros dos encontros formativos -pesquisadora e professora, de aulas e das notas reflexivas da professora sobre seu próprio percurso.

Objetivos: i) Gerais: Analisar os pressupostos teóricos e metodológicos orientadores da organização do ensino sob enfoque da PHC e Ensino Desenvolvimental; ii) Específicos: Identificar os princípios da didática desenvolvimental no processo de ensino e desenvolver o processo de formação das ações mentais ao organizar intencionalmente o processo de ensino de conceitos matemáticos teóricos/científicos. 
Para a concretização dessas inter-relações, a investigação apoiou-se nas discussões do campo da didática, sob o enfoque da perspectiva histórico-cultural e do ensino desenvolvimental de Davidov6 (1986).

As pesquisas de Araújo (2003), Cedro (2008), Scarlassari (2007), Panossian, (2008), Rosa (2009), dentre outros, demonstraram que fragilidade na formação do pensamento teórico dos estudantes, em sua maioria, deve-se ao tipo de organização do ensino nas escolas brasileiras que privilegia uma abordagem dos conceitos de forma superficial.

Conforme Rosa, Cedro e Moraes (2010, p.77), esse tipo de ensino apresenta mais as características da formação do pensamento empírico, baseado na observação dos objetos, na generalização formal e na comparação das propriedades comuns, em detrimento da transformação dos objetos, da generalização teórica e da análise das relações de suas propriedades intrínsecas, que são características do pensamento teórico.

Outro agravante nessa questão - como discutido nos estudos de Moura (2000, 2002), Marco (2009), Puentes \& Longarezi (2013), além de outros - pode estar no fato de que a formação do professor, seja inicial ou continuada, muitas vezes, não possibilita a compreensão da organização do ensino sob o foco da lógica dialética, com finalidade da formação do pensamento teórico do estudante.

Por esse viés didático e dialético o processo formativo da professora esteve consubstanciado pela apropriação teórico-metodológica de um ensino intencionalmente organizado para considerar a base genética em que se forma o conceito, suas características internas definidoras, sem desconsiderar a prática social dos sujeitos, seu pensamento empírico/cotidiano.

Tais questões direcionaram a um enfrentamento, considerando os dois aspectos dessa realidade: ensino e aprendizagem, em suas inter-relações com o processo de desenvolvimento. Para tanto, observaram-se as ações didáticas desse processo. Nessa análise, o objetivo-fim da atividade de ensino (desenvolvimento integral do estudante, apropriação conceitual) constituiu-se em conteúdo e forma do processo formativo docente.

\section{Procedimentos metodológicos}

Na investigação optou-se pelo procedimento de intervenção didático-formativo, fundamentado e organizado sob as bases do materialismo histórico-dialético,

6 Ao longo dessa produção textual adota-se a grafia dos nomes dos autores russos usados no alfabeto ocidental (Vigotski, Davidov, Petrovski), porém nas citações e referências respeita-se a grafia de acordo com a obra original do autor (Vygotski/Vigotsky/Davydov, Petrovsky). 
de alguns elementos da teoria da atividade, do ensino e didática desenvolvimental. Tal procedimento levou em consideração as especificidades da realidade educacional brasileira, ao possibilitar agir de modo teórico-prático nos processos de ensino, aprendizagem e desenvolvimento, tanto da professora, como dos estudantes.

O procedimento de intervenção didático-formativo articulou os três movimentos: pesquisa, ensino e estudo de modo sistêmico e inter-relacionados, uma vez que ocorreram simultaneamente. A organização da pesquisa relacionou-se com a organização do ensino e, esta, por sua vez, com a organização do estudo dos estudantes (ações de aprendizagem), na busca por movimentos de apropriações e objetivações para-si, no decorrer do processo de investigação.

Para tanto, foram realizados quinze encontros de formação com a professora, concomitante ao processo de intervenção com os estudantes, distribuídos ao longo de três semestres. Os registros dos encontros de formação, gravados em áudio, no caderno de campo e nas notas reflexivas da professora, possibilitaram apreender produtos objetivos e subjetivos do seu percurso formativo.

Nesse período, a professora se envolveu em leituras, estudos, diálogos sobre o aporte teórico-metodológico da PHC para se instrumentalizar, a fim de se objetivar em sua prática pedagógica. Ao buscar a essência da ação de ensinar, a professora se aprofundou no estudo sobre os modos e as condições da aula, ou seja, nos elementos didáticos do ensino em sua unidade com a aprendizagem (Objetivos, conteúdo, métodos, meios, formas de organização, avaliação) sob a lógica dialética. Esse movimento se constituiu entre vários confrontos, conflitos, reelaborações, superações que resultaram nas elaborações das atividades orientadoras de ensino, (Moura, 1992), AOE-I-II-III e seus respectivos sistemas de ações de aprendizagem (produtos objetivos e subjetivos). Nessas atividades orientadoras de ensino, desenvolveram-se conceitos teóricos algébricos: equação; equação fracionária e com coeficiente fracionário; equação linear e quadrática; função.

Os dados da totalidade do processo formativo da professora, sob esse enfoque didático e dialético, foram organizados em unidades de análise no sentido atribuído por Vigotski (1991). Tais unidades se aproximaram dos isolados de pesquisa, de Caraça (2002, p.105), pois se constituíram como recorte da realidade, mas contendo a unidade do todo.

Cada um desses isolados foram expressos por episódios, "aqueles momentos em que fica evidente uma situação de conflito que pode levar à aprendizagem do novo conceito" (Moura, 1992, p.77). Para este autor, os episódios evidenciam as unidades de análise, por que revelam "a natureza e qualidade das ações" (Moura, 2000, p.60) da professora. Esses episódios foram organizados em cenas que, ao longo do processo, denotaram as manifestações da professora acerca do sentido do seu trabalho educativo (motivos formadores de sentido). 
Para os propósitos desse artigo, analisa-se uma cena do Episódio A, “As dificuldades de organização do ensino para além da lógica formal”, com as seguintes unidades/isolados de pesquisa compartilhamento/interações; apropriações/ objetivações; atribuição de sentido.

Nessa análise, observou-se o movimento de conscientização da professora das inter-relações da estrutura interna de sua atividade de ensino, no dinamismo sistêmico e dialético dos seus elementos de orientação e execução. As unidades de análise/isolados de pesquisa revelaram como a professora atribuiu sentido às ações na práxis docente, na unidade da atividade prática e teórica.

O procedimento de intervenção didático-formativo, nesse caso, possibilitou criar as condições de trabalhar na estrutura interna da atividade de ensino, na sua relação com a atividade de estudo. No movimento desse processo, foram realizadas ações analítico-reflexivas, para tomar consciência dos motivos-finalidades (ações-orientadas aos conteúdos-objetos-objetivos. Desse modo, a professora constituiu novas necessidades, na estreita relação com o motivo orientado e vinculado ao conteúdo objetivo de ensinar.

Durante o percurso formativo, as ações foram realizadas ativamente pela professora sempre considerando um conteúdo, mediante condições de execução, tendo em vista atender objetivos específicos relacionados elas.

\section{Análise de um Episódio}

Episódio A: As dificuldades de organização do ensino para além da lógica formal

As diversas leituras sobre a formação do pensamento teórico no ensino da álgebra, a partir do enfoque histórico-cultural, suscitaram dúvidas, incertezas e apreensões na professora diante do estabelecido no programa escolar. Instaurou-se uma situação conflitiva que provocaram novas necessidades em si mesma na tentativa de solucioná-la.

\section{Cena A.1 (AOE-I/2012)}

Sujeito Diálogos

Pesq. Afinal, como será que os alunos formam o conceito sob essa base, do abstrato ao concreto?

Profa. $\quad$ Eu fiz um levantamento junto aos estudantes sobre a forma ou a maneira que eles haviam estudado, nos anos anteriores, a equação.

Vocês usaram os princípios multiplicativos, ou a adição e subtração, multiplicando ou somando ou subtraindo, ou vocês querem o processo direto? Como que a professora ensinou o ano passado? Foi tudo por cima assim? Foi o direto. Eu não. Eu explico os dois, para eles escolherem, e deixo a opção de escolha. Antes de passar para um lado negativo e passar para o outro lado positivo, a troca dos sinais, eu poderia ter usado os princípios, só que eu os questionei e eles falaram que aprenderam pelo processo direto "propriedades inversas”. Eu falei ótimo! Para mim, é muito mais fácil. Então, como é que eu faço? Se eu ficar retomando princípios e matérias do ano passado eu não vou conseguir prosseguir com o conteúdo... 
Pesq. $\quad$ Eu entendo sua preocupação, realmente, temos visto os estudantes prosseguirem o seu percurso escolar, passando de um ano para o outro, sem a compreensão dos conceitos, porque, muitas vezes, não conseguem usá-los em outras situações diferentes daquela trabalhada, ou dada na sala de aula. É isso mesmo, que você acabou de relatar, o professor ensina a linguagem formal, usa os símbolos da matemática, mas os estudantes não conseguem entender o porquê desse uso, há um formalismo do conteúdo, a representação ou a linguagem simbólica é supervalorizada em detrimento da linguagem semântica, aquela em que o estudante entende o uso de determinada fórmula pela compreensão da característica essencial do conceito que está sendo formado. Por isso, eles mesmos preferem não mudar também.

Profa . Sabe, se o professor não cumpre o que está estabelecido no programa do CBC, se ele não trabalha tudo que está lá no livro didático, ele não é considerado um bom professor. As avaliações sistêmicas também exigem o cumprimento do conteúdo. Você sabe que dentro da escola, entre os pais e até entre os colegas de trabalho tem a cultura da comparação sobre o que cada um desenvolve na sala de aula, até onde foi trabalhado este ou aquele conteúdo. $\mathrm{O}$ caderno onde o aluno registra o que foi feito na sala de aula é motivo de comparação para certos pais e supervisores. Então, há uma pressão do sistema de ensino, da escola, dos pais e colegas que fica difícil.

Pesq. Bem, pensemos sobre o que está nesses documentos? Determinam-se temas, conteúdos, habilidades, objetivos, mas não há uma preocupação didático-metodológica. A quem cabe essa decisão? Ao professor?! Mas a partir de quais princípios o professor faz essa escolha?

Prof ${ }^{a}$ Geralmente, em cima do material que a gente tem, do livro didático e do CBC e experiência no dia a dia da aula.

Prof ${ }^{\mathrm{a}} \quad$ E como o livro didático aborda os conteúdos? Que metodologia de ensino? Como vemos, neste livro didático adotado, ensina-se pela linguagem formal, pelo treino mecânico das normas e formas de resolução, sem que haja uma ação ativa por parte do aluno, sem uma metodologia que auxilie o aluno para pensar sobre o conceito. Você acha que os estudantes conseguiriam agir de uma forma diferente desta?

Prof ${ }^{\mathrm{a}} \quad$ É, nesta sala temos alunos de classe média e alta vindo para a escola com intenção de brincar, porque sabem que depois os pais contratam um professor particular para sanar as dificuldades. Então, não envolvem muito, não perguntam nada sobre o que não sabem, e assim, fica difícil para o professor. Mas, acho que a gente pode tentar.

Pesq. Vamos tentar partir da linguagem semântica para a linguagem simbólica, com compreensão do que se está fazendo. Isso é princípio didático. Como chegar até isso? Requer uma metodologia de ensino. Vamos tentar trabalhar pelo método da resolução de problemas, onde o aluno vai construindo, com a orientação do professor as características dos conceitos, dando significado a eles. Podemos pensar em uma dinâmica de trabalho que envolva os diferentes grupos e o coletivo para ver como eles vão apreendendo o conceito, e ao mesmo tempo, nós podemos perceber o movimento do motivo diante estudo.

Prof ${ }^{\mathrm{a}}$ Tudo isso é muito difícil para mim. Apesar de sempre preocupar em ensinar bem, confesso que não havia pensado ainda em como o aluno aprende. Estou confusa... Na graduação em matemática eu não estudei sobre isso, tudo era ensinado de uma forma tradicional mesmo. Então, da mesma forma que eu aprendi comecei a fazer com meus alunos, até porque nem nos cursos de formação continuada não há essa preocupação. Se o professor sabe o conteúdo, então, ele sabe ensinar.

Podemos apreender dessa cena que a discussão de textos sobre a álgebra no enfoque da PHC (uma das operações criadas), desencadeou na professora uma situação conflitiva e contraditória. Quanto mais se aproximou das leituras sobre a história de construção dos conceitos inerentes ao campo da álgebra, de sua significação social e do nível de generalização e abstração que tais conceitos envolvem, mais compreendeu que ensinar somente as fórmulas das representações algébri- 
cas e suas resoluções não possibilitam ao estudante o entendimento da essência do conceito.

Apesar de considerar que sempre ensinou "bem", nunca havia pensado em como é que o estudante se apropria de conceitos científicos, ou em como ensiná-los a operar mentalmente. Questões que a colocaram frente a um problema que precisou resolver. Como no trecho: "Então, como é que eu faço? Se eu ficar retomando princípios e matérias do ano passado eu não vou conseguir prosseguir com o conteúdo...”. Esse argumento revela o quanto nas escolas, muitas vezes, a preocupação pedagógica concentra-se mais no ensino dos conteúdos curriculares, do que no processo de orientar o estudante para operar mentalmente com os conceitos, em um tipo de ensino que impulsione o desenvolvimento integral do sujeito. Nesse caso, a professora se deparou com um problema didático e formativo que, os seus conhecimentos e sua experiência docente, não foram suficientes para superá-lo. Isso criou novas necessidades diante de sua atividade de ensino.

Entretanto, a necessidade em si não foi a geradora do movimento, mas o alimentou, pois, ela, só pôde realizar-se no seu objetivo correspondente: a organização didática do ensino de matemática, pela via da formação das ações mentais no estudante. Por sua vez, tal correspondência se efetivou mediante um processo de ações e relações mediadas intencionalmente para esse objetivo. Nossa intenção, nesse dado momento do processo didático-formativo, deteve-se em proporcionar condições para o compartilhamento/interações entre professora, pesquisadora e a realidade concreta. Para isso, a intervenção didático-formativa, mediada pela sua prática pedagógica, favoreceu o confronto entre o tipo de organização do ensino focado no pensamento empírico e no teórico. Além disso, trouxe para as discussões e reflexões, a organização do programa curricular vivenciado pela professora e pelos estudantes na escola.

Na medida em que a professora expôs as condições objetivas de sua atividade e tomou ciência das contradições em que vive sua docência, teve melhores condições de ir colocando-se como sujeito do processo. A necessidade de pensar como organizar o ensino, com ênfase não no conteúdo, mas em como orientar o estudante na apropriação teórica do conceito, passa a ser sua e não somente para efeito da pesquisa que se realizava. Por isso, as interações entre os sujeitos que, juntos compartilham seus problemas, possibilitam também, estabelecer objetivos em comum para resolvê-los. O conflito interno, colocou a professora em movimento, mediado na e pela atividade. Assim nos esclarece Moura (2000):

Isto é, deve provocar no sujeito uma necessidade de solucionar algum problema. Ou, melhor ainda: ter sua nascente numa necessidade. Esta, por sua vez, só aparece diante de um problema que precisa ser resolvido e cuja solução exige uma estratégia de ação. (p.34). 
Por essa razão, os questionamentos da pesquisadora para a professora procuraram colocá-la em condição de atividade e provocaram novas necessidades, como nos trechos "Mas a partir de quais princípios o professor faz essa escolha?"; "Você acha que os estudantes conseguiriam agir de uma forma diferente desta?”. Essas questões procuram ajudar a professora a refletir sobre os aspectos didáticos e dialéticos do ensino-aprendizagem-desenvolvimento. Processos distintos, porém, que se inter-relacionam de forma complexa e são interdependentes entre si.

Por isso, quando a professora abordou as dificuldades dos estudantes aprenderem, no trecho "Eles não envolvem muito, não perguntam nada sobre o que não sabem, e assim, fica difícil para o professor. Mas, acho que a gente pode tentar...", demonstrou a gênese de uma necessidade docente orientada por interesse interno, relacionado com o conteúdo e objetivo do ensino: organização didática e intencional do ensino para o desenvolvimento. Nesse caso, a professora começa a compreender a significação social do ensino, não como um fim em si mesmo, ou somente como um ensino que deve repassar ao estudante um dado conteúdo escolar, mas como uma condição necessária para que os estudantes se "envolvam" (tenham motivos) e desenvolvam o pensamento e novas atitudes diante do objeto a conhecer.

Klingberg (1978) salienta a necessidade e a importância de orientar os professores em seu processo formativo, para que possam realizar um trabalho criativo. Conforme o autor, a professora necessita dominar os processos de "enseñanza" seja, dominar as "leis" ${ }^{8}$ de caráter lógico que atuam nos processos de ensinar e de aprender que, de fato, impulsionem o desenvolvimento.

Considerou-se importante fomentar, no processo didático-formativo da professora, a apropriação dessas leis que regem o ensino e suas relações com aprendizagem e desenvolvimento, por isso, constituíram-se em processo e produto. Os estudos teórico-metodológicos da $\mathrm{PHC}$, vinculados às necessidades do ensino de matemática, atuaram como um instrumento mediador entre a realidade vivida na docência da professora e o objeto do conhecimento. Acreditou-se que o duplo movimento, prático-teórico e teórico-prático, estudo da $\mathrm{PHC}$ e trabalho educativo, realizados

7 Para Klingberg (1978, p.126-7), o conceito de “enseñanza" compreende-se como processos que envolvem tanto a instrução como a educação, e que, nesses processos atuam diferentes leis de caráter lógico vinculadas à concepção dialético-materialista. Tais leis atuam objetivamente mediante a conduta subjetiva do professor e estudantes. Por isso, o autor defende o duplo sentido desse conceito: como fenômeno social (tem uma história, é um fenômeno que tem se desenvolvido historicamente e continua desenvolvendose ininterruptamente) e como acontecimento pedagógico (um processo em constante movimento que tem lógica e dinâmica internas).

8 Conforme Klingberg (1978, p.128), por lei se entende uma relação objetiva, necessária, geral e essencial entre circunstâncias e processos da natureza, da sociedade e do pensamento. As leis estão muito vinculadas ao processo de "enseñanza", elas atuam como leis didáticas ou pedagógicas em contínua inter-relação e de forma complexa. 
na sala de aula e fora dela, ajudaram a professora atribuir novos significados aos processos de ensino-aprendizagem.

Esse movimento possibilitou a atividade compartilhada e despertou o olhar da professora para os aspectos internos do método de ensino e aprendizagem, salientados por Klingberg (1978, p. 292), como aqueles procedimentos e operações lógicas que provocam a atividade criadora independente dos estudantes. Quando a professora afirmou, no trecho "Apesar de sempre preocupar em ensinar bem, confesso que não havia pensado ainda em como o aluno aprende. Estou confusa... ", demonstrou a tomada de consciência do aspecto interno do método de ensino. O conteúdo desse argumento revelou uma questão muito importante nos processos formativos docentes, a saber: oportunizar espaços para compartilhar significados sobre ensinar, aprender, desenvolver-se e sobre a função social da escola, a fim de que os sujeitos considerem o conhecimento que possuem e, na interação com os demais, possam reelaborá-los, bem como, a si mesmos nesse processo. Desse modo, no domínio consciente e voluntário sobre como organizar o processo de formação das ações mentais nos estudantes, a professora se desenvolveu e exerceu seu potencial criador no trabalho educativo, de forma independente.

Na continuidade do mesmo trecho, observou-se que a professora passou a identificar as especificidades do ensino e da aprendizagem, bem como, suas inter-relações complexas: "Na graduação em matemática eu não estudei sobre isso, tudo era ensinado de uma forma tradicional mesmo. Então, da mesma forma que eu aprendi comecei a fazer com meus alunos, até porque nem nos cursos de formação continuada não há essa preocupação. Se o professor sabe o conteúdo, então, ele sabe ensinar”. Por isso, acredita-se que, se o conflito gerado naquele contexto não estivesse mediado pela essência do ensino desenvolvimental, o qual desenvolve o pensamento teórico e, se não realizasse por meio de ações lógicas e abstratas desse tipo de pensamento, poderia resultar somente na reprodução mecânica dessas informações.

Para contribuir com os movimentos de superação desses conflitos, a intervenção didático-formativa previu estudos teórico-metodológicos da PHC nos 15 encontros formativos que, se constituíram como operação e não se esgotaram em si mesmos, porque passaram a compor outra relação com as ações necessárias para a organização do ensino. Dentre elas, análise, reflexão, síntese do modo geral de ação com conceitos teóricos, que passaram a ser realizados ativamente pela professora durante o percurso. Essas ações, desenvolvidas de forma participativa e, mediante a elaboração colaborativa das atividades orientadoras de ensino, ofereceram as condições para que a professora constituísse novas relações com os estudantes, tendo em vista apropriações de conceitos teóricos. Nesse processo didático-formativo, a professora apropriou-se de um referencial teórico e se objetivou no ensino, desenvolvendo as AOE. Conforme, Moura; Araújo; Ribeiro; Panossian; Moretti. (2010, p.100): 
A AOE constitui-se um modo geral de organização do ensino, em que seu conteúdo principal é o conhecimento teórico e seu objeto é a constituição do pensamento teórico do indivíduo no movimento de apropriação do conhecimento. Assim, o professor, ao organizar as ações que objetivam o ensinar, também requalifica seus conhecimentos, e é esse processo que caracteriza a AOE como unidade de formação do professor e do estudante. (Moura et al., 2010, p.100).

A construção compartilhada e dialogada das atividades orientadoras de ensino, realizadas durante a intervenção, possibilitaram o aprofundamento didático do ensino impulsionador do desenvolvimento de novas funções psíquicas, tanto da professora quanto dos estudantes. Porque ao discutir conteúdo, métodos, formas de organização e objetivo das ações de aprendizagem; bem como, tarefas correspondentes a serem realizadas pelos estudantes - para que esses desenvolvessem o seu pensamento teórico - a professora objetivou sua necessidade no conteúdo e objetivo de sua atividade. Nessa correlação, atividade-necessidade-objeto (conteúdo), com as ações, objetivos e condições ocorreu a atribuição de sentido às diversas ações (didáticas) da sua docência, estas, deixaram de operar como um fim em si mesmo.

Esse movimento possibilitou processos de apropriação/objetivação da docência, os quais se efetivaram no âmbito mais humanizador. Por isso, como processos não foram tomados como conclusivos. As novas relações constituídas pela professora entre o trabalho educativo e o seu estudo formativo, oportunizaram as condições objetivas e subjetivas de atuar, criar e transformar as relações com seus estudantes.

\section{Considerações}

A objetivação genérica para-si da professora se materializou, no campo da educação escolar, na medida em que possibilitou aos estudantes apropriações e objetivações genéricas para-si, nas atividades de estudo que eles realizaram sob sua orientação e no coletivo. Por isso, o processo de organizar o ensino e orientar a formação das ações mentais para apropriação de conceitos, operou como objetivo-meio, efetivou-se como conteúdo e forma do processo formativo docente, com vistas ao alcance do seu objetivo-fim: desenvolvimento integral dos estudantes. A materialização desses processos de apropriação/objetivação, na esfera da genericidade para-si, possibilitou a humanização dos sujeitos em suas singularidades.

As contribuições da PHC da atividade e do ensino desenvolvimental para o processo formativo docente - expressos por essas análises do episódio de ensinoevidenciam que: $\mathrm{O}$ ensino e a aprendizagem, na sua relação com o desenvolvimento, tornam-se conteúdo e forma do seu percurso formativo. A organização do ensino, intencionalmente planejado para desenvolver novas capacidades mentais nos estu- 
dantes,- o pensamento teórico e a apropriação de conceitos teóricos, nesse caso, os conceitos matemáticos algébricos,- se constituiu o conteúdo do processo formativo.

A pesquisa demonstrou, que o processo formativo docente desenvolvido concomitante ao trabalho educativo, ofereceu à professora possibilidade de apropriação do referencial teórico-metodológico da PHC da atividade e do ensino desenvolvimental, tendo em vista a organização do ensino para o desenvolvimento. Tal apropriação ocorreu no âmbito para-si, pois esteve consciente da importância da sua participação nas produções humano-genéricas da humanidade: ensinar para formar o pensamento teórico dos estudantes. Portanto, as suas objetivações na realidade da escola e da aula, ocorreram, também, no âmbito para-si. Nesse processo de intervenção didático-formativo, a professora identificou os conceitos teóricos presentes nos conteúdos escolares, definiu os objetivos, a forma de organização da aula, selecionou os métodos de ensino, as ações e tarefas específicas a serem realizadas pelos estudantes, tendo em vista a apropriação conceitual no nível teórico e alcançou a finalidade do o ensino, ou seja, a promoção da aprendizagem e o desenvolvimento integral do estudante. Por isso, o ensino e a aprendizagem, na sua relação com o desenvolvimento, se constituíram na forma e conteúdo do processo formativo docente.

Tais resultados sinalizaram a organização do processo de formação docente em consonância com a estrutura psicológica das atividades de ensino e estudo. Esse processo direcionado a fins claros e conscientes, por parte dos envolvidos, impulsionou o desenvolvimento da professora, bem como, dos seus motivos para ensinar conceitos teóricos.

\section{Referências}

Araújo, E. S. (2003). Da formação e do formar-se: a atividade de aprendizagem docente em uma escola pública. Tese de Doutorado em Educação. São Paulo: Universidade de São Paulo.

Caraça, B. J. (2002). Conceitos fundamentais da Matemática. Lisboa: Gradiva. 4a Edição.

Cedro, W. L. (2008). O motivo e a atividade de aprendizagem do professor de matemática: uma perspectiva histórico-cultural. Tese de Doutorado em Educação. São Paulo: Universidade de São Paulo.

Davidov, V. V. (1986). Problemas do ensino desenvolvimental: a experiência da pesquisa teórica e experimental na psicologia. Tradução de José Carlos Libâneo e Raquel A. M. da Madeira Freitas. Revista Soviet Education, August, v. XXX, n. 8. Acesso em 10 de agosto de 2015. Disponível em: http://professor.pucgoias.edu.br/SiteDocente/admin/arquivosUpload/5146/material/DAVYDOV\%20TRADU\%C3\%87\%C3\%830\%20PROBLEMS\%20 OF\%20DEVELOPMENTAL\%20TEACHING\%20(Livro).doc.

Klingberg, L. (1978). Intoducción a la Didáctica General. Editorial Pueblo y Educación, Playa, Ciudad de La Habana.

Leontiev, A. N. (1974). Problemas del desarrollo del psiquismo. 2. Ed. La Habana: Editorial Pueblo y Educación. 
. (1978). O desenvolvimento do psiquismo. Lisboa: Horizonte Universitário.

(197[-]). O desenvolvimento do psiquismo. Traduzido do francês por Manoel Dias Duarte. 1. ed. Editora Moraes.

Marco, F. F. de. (2009). Atividades computacionais de ensino na formação inicial do professor de matemática. Tese de Doutorado em Educação. Campinas: Universidade Estadual de Campinas. Acesso em 15 de julho de 2015. Disponível em: http://www.bibliotecadigital. unicamp.br/document/?code $=000468556$.

Moura, M. O. (1992). A construção do signo numérico em situação de ensino. Tese de Doutorado em Educação. São Paulo: Universidade de São Paulo.

. (2000). O educador matemático na coletividade de formação: uma experiência com a escola pública. Tese de Livre-Docência em Educação. São Paulo: Universidade de São Paulo.

(2002). A atividade de ensino como ação formadora. In: Castro, A. D. \& Carvalho, A. M. P. de (Org.). Ensinar a ensinar: didática para a escola fundamental e média. São Paulo: Pioneira Thomson Learning.

Moura, M. O; Araújo, E. S.; Ribeiro, F. D.; Panossian, M. L. \& Moretti, V. D. (2010). Atividade Orientadora de Ensino como unidade entre ensino e aprendizagem. In: Moura, M. O. (Org.). A atividade pedagógica na teoria histórico-cultural. Brasília: LíberLivro.

Panossian, M. L. (2008). Manifestações do pensamento e da linguagem algébrica de estudantes: indicadores para a organização do ensino. Dissertação de Mestrado em Educação. São Paulo: Universidade de São Paulo.

Puentes, R. V. \& Longarezi, A. M. (2013). Escola e didática desenvolvimental: seu campo conceitual na tradição da teoria histórico-cultural. Educação em Revista. 29 (1), 247-271. Disponível em: http://www.scielo.br/pdf/edur/v29n1/aop_224.pdf.

Rosa, V. M. G. (2009). Aprendizagem da equação do 2o grau: Uma análise da utilização da teoria do ensino desenvolvimental. Dissertação de Mestrado em Educação. Goiânia: Universidade Católica de Goiás.

Rosa, J. E.; Moraes, S. P. G. \& Cedro, W. L. (2010). As particularidades do pensamento empírico e do pensamento teórico na organização do ensino. In: Moura (Org.). A atividade pedagógica na teoria histórico-cultural. Brasília: LíberLivro.

Scarlassari, N. T. (2007). Um Estudo de dificuldades ao aprender álgebra em situações diferenciadas de ensino de alunos da 6ª série do ensino fundamental. Dissertação de Mestrado. Campinas: Universidade Estadual de Campinas. Acesso em 14 de março de 2015. Disponível em: http://www.bibliotecadigital.unicamp.br/document/?code=vtls000421677\&fd=y.

Vigotski, L. S. (1991). Obras Escogidas, tomo I. Madri: Visor e MEC. . (1984). A formação Social da mente. São Paulo: Martins Fontes.

. (2001). Estudio del desarrollo de los conceptos científicos en la edad escolar. In: Obras Escogidas. Tomo II. Problemas de Psicología General. 2. edición. Madrid: A. Machado libros.

Submetido em: 21/01/2016

Aceito em: 28/02/2016 